\title{
Peptidomics Analysis Discloses That Novel Bioactive Peptides Participate in Necrotizing Enterocolitis in a Rat Model
}

\author{
Yiwen Liu, ${ }^{1}$ Changlin Wang, ${ }^{1}$ Renqiang Yu, ${ }^{2}$ Jianfeng Fan, ${ }^{3}$ Weilai Jin, ${ }^{1}$ Yuting Zhu, ${ }^{1}$ \\ Yingzuo Shi, ${ }^{3}$ Yulei Jing, ${ }^{3}$ Xiaolei Wang, ${ }^{1}$ Zhengying Li $\mathbb{D},{ }^{1}$ Jian Zhou $\mathbb{D},{ }^{4}$ and Le Zhang $\mathbb{D}^{1}$ \\ ${ }^{1}$ Department of Neonatology, The Affiliated Wuxi Children's Hospital of Nanjing Medical University, Wuxi, 214023 Jiangsu, China \\ ${ }^{2}$ Department of Neonatology, The Affiliated Wuxi Maternity and Child Health Care Hospital of Nanjing Medical University, Wuxi, \\ 214002 Jiangsu, China \\ ${ }^{3}$ Department of Pediatrics Surgery, The Affiliated Wuxi Children's Hospital of Nanjing Medical University, Wuxi, \\ 214023 Jiangsu, China \\ ${ }^{4}$ Department of Pediatric Laboratory, The Affiliated Wuxi Children's Hospital of Nanjing Medical University, Wuxi, \\ 214023 Jiangsu, China
}

Correspondence should be addressed to Zhengying Li; lizhy@njmu.edu.cn, Jian Zhou; jianzhou@njmu.edu.cn, and Le Zhang; zhle@njmu.edu.cn

Received 27 June 2020; Revised 6 December 2020; Accepted 17 December 2020; Published 31 December 2020

Academic Editor: Rafael S. De Molon

Copyright (c) 2020 Yiwen Liu et al. This is an open access article distributed under the Creative Commons Attribution License, which permits unrestricted use, distribution, and reproduction in any medium, provided the original work is properly cited.

Necrotizing enterocolitis (NEC) is a common devastating gastrointestinal disease in premature infants, the molecular mechanisms of which have not been fully elucidated. Recently, endogenous peptides have garnered much attention owing to their role in diagnosis and treatment. However, changes in the peptide expression of NEC intestinal tissues remain poorly understood. In the present study, a comparative peptidomics profiling analysis was performed between NEC and control intestinal tissues via liquid chromatography-tandem mass spectrometry (LC-MS). In total, 103 upregulated and 73 downregulated peptides were identified in the intestinal tissues (fold change $\geq 1.5, p<0.05$ ). Bioinformatics analysis revealed that these differentially expressed peptides were significantly associated with NEC pathophysiology, including apoptosis, the TGF- $\beta$ signaling pathway, the Wnt signaling pathway, and the MAPK signaling pathway. Furthermore, two putative peptides could inhibit apoptosis and promote the migration of intestinal epithelial cells induced by lipopolysaccharide; these peptides were derived from the protein domains MT1 and EZRI, respectively. In conclusion, our study revealed that endogenous peptides are involved in the pathophysiologic mechanism of NEC; nevertheless, further exploration is required in this regard.

\section{Introduction}

Necrotizing enterocolitis (NEC) is one of the most common fatal diseases in preterm infants, with an incidence rate of 5$10 \%$ in very low birthweight $(<1500 \mathrm{~g})$ cases [1]. Some studies suggest that the administration of steroids, immunoglobulins, or Lactobacillus can reduce the incidence of NEC in neonates. However, the current treatment strategies predominantly focus on medical stabilization and the prevention of disease progression [2]. The mortality rate may rise to $50 \%$ when irreversible necrosis or perforation that requires surgery is present [3]. It is known that the disease progresses primarily via the invasion of inflammatory factors and bacteria in the gastrointestinal tract; however, the underlying molecular mechanisms remain to be elucidated completely [4].

Peptidomics, a novel branch of proteomics, has garnered considerable attention for its role as biological markers and therapies [5]. Recently, peptidomics analyses have been applied in detecting peptide changes in different diseases, including cancer $[6,7]$. Increasing evidence has shown that endogenous peptides play a crucial role in digestive system diseases [8]. For instance, trefoil factor family peptide 3 (TFF3), mainly located in goblet cells, is significantly upregulated in peptic ulcer. TFF3 not only participates in maintaining and repairing mucosal integrity but also promotes the healing of intestinal ischemia-reperfusion injury in 


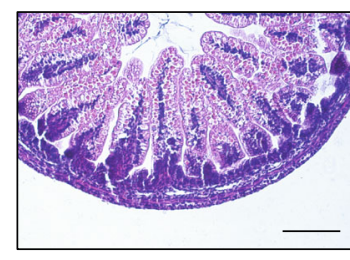

Ctrl

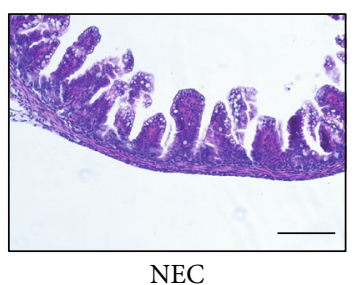

(a)

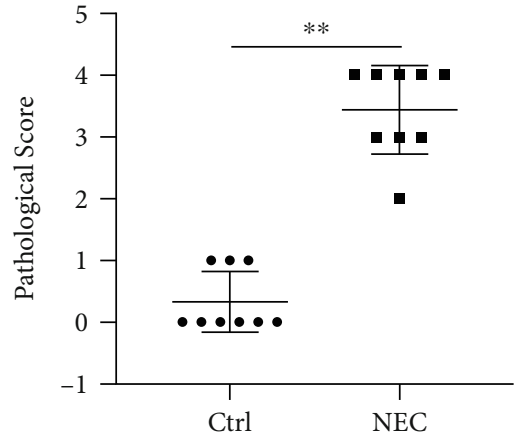

(b)

Figure 1: Establishment of the NEC model: (a) H\&E staining of representative intestinal tissue sections from the Ctrl and NEC groups (bar $=100 \mu \mathrm{m}$ ); (b) pathological scores of representative intestinal tissue sections from the Ctrl and NEC groups $\left({ }^{* * *} p<0.001\right)$.

weaned rats [9]. Therefore, an analysis of differentially expressed peptides in NEC tissues may provide new insights to explore treatment strategies.

To explore the peptide expression profile of NEC, quantitative liquid chromatography-mass spectrometry (LC-MS) was performed, and the peptide content of rat NEC intestinal tissue (NEC group) and normal control intestinal tissue (Ctrl group) was analyzed. Based on preliminary functional verification, two downregulated peptides derived from the EZRI (EDP1) and MT1 (MDP2) domains showed a significant protective effect in a lipopolysaccharide- (LPS-) induced NEC model in vitro and are worthy of further study.

\section{Materials and Methods}

2.1. Ethics Statement. The study was conducted with the approval of the Animal Ethics Committee of Nanjing Medical University (No: IACUC-1807004). To minimize the suffering of the animals used in this research, the procedures followed were in strict compliance with the Guide for the Care and Use of Laboratory Animals.

2.2. Establishment of the Animal Model. Eighteen neonatal Sprague-Dawley rats provided by the Animal Core Facility of Nanjing Medical University were randomly assigned to the Ctrl and NEC groups. The rats in the Ctrl group were fed by their mothers as needed; the NEC rat model was established as follows [10]: (1) hypoxia-cold stimulation: asphyxia stress via exposure to $95 \%$ nitrogen twice a day for $5 \mathrm{~min}$, followed by exposure to a cold temperature $\left(4^{\circ} \mathrm{C}\right)$ for $10 \mathrm{~min}$; (2) formula feeding (ionized water $(10 \mathrm{~mL})$ and Esbilac (PetAg) canine milk (5 mL) $(2: 1)$ mixed with Similac Advance infant formula (Abbott Nutrition) $2 \mathrm{~g}$ ): the animals received perfused hypertonic milk $(0.08-0.1 \mathrm{~g} / \mathrm{kg})$ immediately after cold stimulation. Four days for establishing the model, the rats were sacrificed, and intestinal tissue was collected. Intestinal tissue $(3 \mathrm{~cm})$ from the terminal ileum was harvested and subjected to NEC model determination and peptide extraction.

2.3. Peptide Extraction and Purification. Three pairs of intestinal tissue samples from the Ctrl and NEC groups were ground into powder in liquid nitrogen and fully compatible with denaturing buffers including $8 \mathrm{M}$ urea/100 $\mathrm{mM}$ TEAB (pH 8.0), $1 \mathrm{mM}$ PMSF, $2 \mathrm{mM}$ EDTA, and $10 \mathrm{mM}$ DTT. The mixture was sonicated on ice for $10 \mathrm{~min}$ and centrifuged at $4^{\circ} \mathrm{C}(12,000 \mathrm{rpm})$ for $30 \mathrm{~min}$; then, the supernatant was transferred to a fresh centrifuge tube. MWCO $(10 \mathrm{kDa})$ filter tubes (Millipore, Billerica, MA, USA) were used to filter the supernatant. The filter tubes were centrifuged at $4^{\circ} \mathrm{C}(10,000 \times \mathrm{g})$; flow-through containing the peptides was collected and purified using a C18 column. Finally, the flow-through was dried under vacuum and stored at $-80^{\circ} \mathrm{C}$.

2.4. TMT Labeling and LC-MS Analysis. Formic acid (0.1\%) was used to dissolve the peptide samples, followed by reducing in $10 \mathrm{mM}$ DTT and alkylating with $50 \mathrm{mM}$ iodoacetamide for $30 \mathrm{~min}$. Following desalting and lyophilization, the peptides were labeled with TMT reagent (TMT 6 Relabeling Reagent, Thermo Fisher Scientific, USA). The labeled peptides were mixed and analyzed via LC-MS/MS [11]; an LTQ-Orbitrap Velos mass spectrometer (Thermo Fisher Scientific) was used for this mass spectrometry analysis. In total, 2000 single emission spectra were accumulated from 10 random positions of each sample. Using isotope correction factors recommended by the manufacturer, search for MS data using MASCOT database (Matrix Science, Boston, MA, USA) and SwissProt database. Additionally, to reduce the possibility of erroneous peptide identification, only those peptides with a significance score $(\geq 20)$ within a $99 \%$ confidence interval and greater than "identity" were counted via MASCOT probability analysis [12].

2.5. Bioinformatics Analysis. The characteristics of the identified peptides were analyzed using ProtParam tool. Presumed functions on peptides and protein-protein interactions were predicted using the UniProt and STRING databases. We used DAVID v6.7 (Database for Annotation, Visualization and Integrated Discovery; https://david-ncifcrf.gov/) for conducting GO and KEGG pathway enrichment analyses to investigate the potential functions of peptides and their precursor proteins.

2.6. Hematoxylin-Eosin Staining (HぬE Staining). After sacrifice, intestinal tissue from the rats' terminal ileum was 
TABLE 1: Differential peptides in the intestine tissue of NEC rat model.

\begin{tabular}{|c|c|c|c|c|}
\hline Accession & Gene & Peptide & Fold change & $p$ value \\
\hline \multicolumn{5}{|c|}{ Upregulated peptides } \\
\hline G3V8B3 & Hist1h2bq & AVTKYTSSK & 57.72612 & $<0.05$ \\
\hline P69897 & Tubb5 & FVFGQSGAGNN & 31.84287 & $<0.01$ \\
\hline Q10758 & Krt8 & DGKLVSESSDIMSK & 25.55914 & $<0.001$ \\
\hline Q10758 & Krt8 & LVSESSDIMSK & 22.05736 & $<0.001$ \\
\hline P15999 & Atp5a1 & VGLKAPGIIPR & 21.49717 & $<0.001$ \\
\hline O88989 & Mdh1 & VIVVGNPANTNCLTASK & 12.14385 & $<0.05$ \\
\hline Q66HT1 & Aldob & ALQASALAAWGGK & 11.93121 & $<0.001$ \\
\hline G3V8B3 & Hist1h2bq & LLLPGELAKH & 11.86002 & $<0.001$ \\
\hline P04182 & Oat & ALQDPNVAAF & 11.16052 & $<0.05$ \\
\hline P05197 & Eef2 & VFSGVVSTGLKVR & 10.57569 & $<0.05$ \\
\hline Q10758 & Krt8 & QPGFGSVGGSST & 10.57101 & $<0.01$ \\
\hline F1LNF1 & Hnrnpa2b1 & GFGFVTF & 10.55872 & $<0.05$ \\
\hline K7S2S2 & Hist2h2aa3 & AGLQFPVGR & 10.3368 & $<0.05$ \\
\hline Q7M0E3 & Dstn & FLWAPEQAPLKSK & 10.01604 & $<0.01$ \\
\hline Q10758 & Krt8 & GGLTSPGFS & 9.126557 & $<0.001$ \\
\hline M0R7B4 & Hist1h1d & SGVSLAALKK & 8.945185 & $<0.001$ \\
\hline Q10758 & Krt8 & FQPGFGSVGGSST & 8.793551 & $<0.001$ \\
\hline P69897 & Tubb5 & FVFGQSGAGN & 8.771316 & $<0.05$ \\
\hline D3ZGY4 & Gapdh-ps2 & GAAQNIIPASTGAAKAVGK & 8.399639 & $<0.001$ \\
\hline D3ZBN0 & Hist1h1b & SLVSKGTLVQTK & 8.352781 & $<0.01$ \\
\hline M0R7B4 & Hist1h1d & GILVQTKGTGASGS & 8.334644 & $<0.001$ \\
\hline P02262 & NA & VGAGAPVYL & 8.301511 & $<0.001$ \\
\hline Q10758 & Krt8 & GMSSFQPGFGSVGGSST & 8.18755 & $<0.01$ \\
\hline P10719 & Atp5b & IGLFGGAGVGK & 7.935978 & $<0.01$ \\
\hline B5DEM5 & Rpl14 & AAIAAAAAAK & 7.751116 & $<0.01$ \\
\hline K7S2S2 & Hist2h2aa3 & GLQFPVGR & 7.629358 & $<0.05$ \\
\hline P62630 & Eef1a1 & ESFSDYPPLGR & 7.607978 & $<0.001$ \\
\hline O55159 & Epcam & QKDCVCNNYKLTSR & 7.485879 & $<0.001$ \\
\hline P15865 & Hist1h1e & SETAPAAPAAPAPAEKTPIKKK & 7.38236 & $<0.01$ \\
\hline D3ZGY4 & Gapdh-ps2 & VKVGVNGFGR & 7.332894 & $<0.001$ \\
\hline F1M577 & LOC 100359671 & AFIAHPKLGK & 6.954795 & $<0.05$ \\
\hline Q6P725 & Des & TFGGAPGFSLGSPLS & 6.720618 & $<0.05$ \\
\hline G3V8B3 & Hist1h2bq & LLLPGELAK & 6.595403 & $<0.01$ \\
\hline D3ZIE9 & Aldh18a1 & VGLGGMEAKVK & 6.321181 & $<0.001$ \\
\hline Q925G0 & Rbm3 & DYSGSQGGYDRYSGGN & 6.259407 & $<0.01$ \\
\hline Q10758 & Krt8 & SFQPGFGSVGGSST & 6.237045 & $<0.01$ \\
\hline Q10758 & Krt8 & SSFQPGFGSVGGSST & 6.119025 & $<0.01$ \\
\hline Q9QXQ0 & Actn 4 & STALYGESDL & 5.964186 & $<0.001$ \\
\hline Q10758 & Krt8 & GSLGGFGGAGVGGIT & 5.600793 & $<0.05$ \\
\hline P05065 & Aldoa & ALQASALK & 5.474993 & $<0.01$ \\
\hline M0RA08 & Plin3 & VTGAVDVTCGAVK & 5.466526 & $<0.001$ \\
\hline Q6P9V9 & Tubalb & VAEITNACFEPAN & 5.315759 & $<0.05$ \\
\hline A0A0G2K3Z9 & NA & SSGNAKIGHPAPSFK & 4.969645 & $<0.01$ \\
\hline Q66H80 & Arcn1 & VLLAAAVCTK & 4.865557 & $<0.05$ \\
\hline D3ZGY4 & Gapdh-ps2 & ALNDNFVK & 4.838244 & $<0.05$ \\
\hline В0К031 & Rpl7 & IALTDNSLVAR & 4.834916 & $<0.001$ \\
\hline P62268 & Rps23 & KANPFGGASHAK & 4.801351 & $<0.001$ \\
\hline
\end{tabular}


TABle 1: Continued.

\begin{tabular}{|c|c|c|c|c|}
\hline Accession & Gene & Peptide & Fold change & $p$ value \\
\hline D3Z7Y6 & Krt20 & LGVAPSVYGGAGGHGT & 4.677876 & $<0.001$ \\
\hline Q10758 & Krt8 & KLEVDPNIQAVR & 4.663074 & $<0.001$ \\
\hline D3ZBN0 & Hist1h1b & SLVSKGTLVQTKGTGASGSF & 4.551461 & $<0.01$ \\
\hline M0R7B4 & Hist1h1d & SGVSLAALK & 4.443164 & $<0.01$ \\
\hline P05197 & Eef2 & VNFTVDQIR & 4.417121 & $<0.01$ \\
\hline V5QR27 & NA & FPGQPGGPGA & 4.341792 & $<0.05$ \\
\hline P63029 & Tpt1 & LDYREDGVTPF & 4.230072 & $<0.05$ \\
\hline Q5EB49 & Enol & SFRNPLAK & 4.118444 & $<0.05$ \\
\hline Q80ZE7 & Cd2ap & GLPAGGIQPHPQTK & 3.871932 & $<0.01$ \\
\hline M0R7B4 & Hist1h1d & ASGPPVSELITK & 3.803902 & $<0.001$ \\
\hline P18420 & Psmal & LVSLIGSK & 3.745425 & $<0.05$ \\
\hline P13437 & Acaa2 & GVFIVAAK & 3.727173 & $<0.01$ \\
\hline D3ZGY4 & Gapdh-ps2 & GAAQNIIPASTGAAK & 3.718082 & $<0.001$ \\
\hline Q10758 & Krt8 & SLGGFGGAGVGGIT & 3.670916 & $<0.001$ \\
\hline D3ZBN0 & Hist1h1b & ALAAGGYDVEKNNSR & 3.654154 & $<0.05$ \\
\hline Q9WVK7 & Hadh & TGEGFYKYK & 3.578854 & $<0.01$ \\
\hline $\mathrm{K} 7 \mathrm{~S} 2 \mathrm{~S} 2$ & Hist2h2aa3 & AGLQFPVGRVH & 3.386712 & $<0.05$ \\
\hline A0A0G2K6S9 & Myh11 & STVAALEAK & 3.278155 & $<0.01$ \\
\hline P06302 & Ptma & SDAAVDTSSEITTK & 3.185452 & $<0.05$ \\
\hline G3V779 & Lad1 & TEVLVTPAGVASK & 3.18017 & $<0.01$ \\
\hline B2GVB1 & S100a6 & LIYNEALK & 3.138931 & $<0.001$ \\
\hline K7S2S2 & Hist2h2aa3 & AEILELAGNAAR & 3.121051 & $<0.01$ \\
\hline P69897 & Tubb5 & YNEATGGKYVPR & 3.110143 & $<0.05$ \\
\hline D3Z7Y6 & Krt20 & SLSSSSQGPALSTSGSL & 3.061158 & $<0.05$ \\
\hline P63018 & Hspa8 & SKGPAVGIDLGTT & 3.057092 & $<0.05$ \\
\hline A0A0G2JWK7 & Tagln & EFTDSQLQEGK & 3.027585 & $<0.05$ \\
\hline P62630 & Eefla1 & QTVAVGVIK & 3.020094 & $<0.05$ \\
\hline P21913 & Sdhb & AQTAAAAAPRIK & 2.929567 & $<0.01$ \\
\hline Q5RJK6 & Inpp1 & LIQSLGPLKT & 2.899027 & $<0.01$ \\
\hline P10860 & Glud1 & VVQGFGNVGLH & 2.760697 & $<0.05$ \\
\hline P47875 & Csrp1 & GFGFGQGAGALVH & 2.639933 & $<0.001$ \\
\hline Q63191 & Mamdc4 & ADQVTLPESITSNP & 2.631403 & $<0.01$ \\
\hline Q07936 & Anxa2 & STVHEILCKL & 2.621438 & $<0.001$ \\
\hline P06302 & Ptma & AAVDTSSEITTK & 2.568546 & $<0.01$ \\
\hline Q3MHS9 & Cct6a & AAVKTLNPKAEVAR & 2.554117 & $<0.05$ \\
\hline P38552 & Lgals4 & YPSAGYNPPQ & 2.508311 & $<0.05$ \\
\hline P05197 & Eef2 & VAVEAKNPADLPK & 2.48379 & $<0.01$ \\
\hline Q5RKI0 & Wdr1 & SVADGYSENNVF & 2.474195 & $<0.001$ \\
\hline G3V8B3 & Hist1h2bq & HAVSEGTKAVTKYTSSK & 2.468693 & $<0.05$ \\
\hline Q6URK4 & Hnrnpa3 & YGGGGNYNDFGN & 2.394012 & $<0.05$ \\
\hline Q6VPP3 & Clca4 & DTQPVLENFSR & 2.382552 & $<0.05$ \\
\hline P12346 & $\mathrm{Tf}$ & LLEACTFHKS & 2.333879 & $<0.05$ \\
\hline P63029 & Tpt1 & GAIDDSLIGGN & 2.312302 & $<0.001$ \\
\hline Q10758 & Krt8 & GGFGGAGVGGIT & 2.276436 & $<0.05$ \\
\hline Q07936 & Anxa2 & STVHEILCK & 2.247658 & $<0.01$ \\
\hline P00731 & Cpal & ALSTDSFNYATYH & 2.173098 & $<0.05$ \\
\hline Q6URK4 & Hnrnpa3 & SGSPYGGGYGSGGGSGGYGS & 2.128543 & $<0.05$ \\
\hline P38552 & Lgals4 & YPSAGYNPPQMN & 2.11776 & $<0.001$ \\
\hline
\end{tabular}


TABle 1: Continued.

\begin{tabular}{|c|c|c|c|c|}
\hline Accession & Gene & Peptide & Fold change & $p$ value \\
\hline Q4FZY0 & Efhd2 & ATDELASKLSR & 2.05165 & $<0.05$ \\
\hline A0A0G2QC04 & Pls1 & EGITAIGGTSSI & 2.004625 & $<0.01$ \\
\hline P38552 & Lgals4 & PAYPSAGYNPPQMN & 1.905471 & $<0.001$ \\
\hline Q9Z144 & Lgals2 & SEKFEVTNLNMK & 1.899939 & $<0.05$ \\
\hline D3ZVN3 & Fbxo10 & HNAEAGVDIR & 1.77112 & $<0.05$ \\
\hline G3V779 & Lad1 & QQVVGAVQAPGQEKVE & 1.722176 & $<0.01$ \\
\hline P46462 & $\mathrm{Vcp}$ & AVANETGAF & 1.668905 & $<0.001$ \\
\hline D4A3Z8 & Tmco3 & LRIRPTQSV & 1.649045 & $<0.05$ \\
\hline \multicolumn{5}{|c|}{ Downregulated peptides } \\
\hline A0A0G2K890 & Ezr & FVIKPIDKK & -1.50403 & $<0.05$ \\
\hline Q9JJ19 & Slc9a3r1 & EALVEPASESPRPA & -1.52587 & $<0.05$ \\
\hline K7S2S2 & Hist2h2aa3 & AQGGVLPNIQAV & -1.53578 & $<0.05$ \\
\hline P15865 & Hist1h1e & APAAPAAPAPAEKTP & -1.57197 & $<0.001$ \\
\hline F1M4J0 & Rictor & STELLLGV & -1.57785 & $<0.05$ \\
\hline A0A0G2JUA5 & Ahnak & DVDVQGPDWH & -1.61943 & $<0.01$ \\
\hline Q63191 & Mamdc4 & NADQVTLPESITSNP & -1.64595 & $<0.05$ \\
\hline Q6P9V9 & Tubalb & DLEPTVIDEVR & -1.66594 & $<0.05$ \\
\hline B5DFA0 & Vil1 & EENQVITPRLF & -1.69645 & $<0.05$ \\
\hline A0A0G2K3K2 & Actb & NELRVAPEEHPV & -1.70784 & $<0.05$ \\
\hline Q63191 & Mamdc4 & QVTLPESITSNP & -1.7079 & $<0.05$ \\
\hline D3ZDZ1 & Apbblip & LPPРPPPP & -1.72276 & $<0.01$ \\
\hline Q5EB49 & Eno1 & KLNVVEQEKIDQLMIEMDGTENK & -1.7416 & $<0.05$ \\
\hline P62630 & Eefla1 & GVGEFEAGISKN & -1.78783 & $<0.01$ \\
\hline P63269 & Actg2 & FAGDDAPRAVFPS & -1.81415 & $<0.001$ \\
\hline D3ZBN0 & Hist1h1b & GTGASGSFKLN & -1.85091 & $<0.001$ \\
\hline D3ZAU0 & Muc5b & ITFCEGSCSGK & -1.90446 & $<0.05$ \\
\hline P06302 & Ptma & SDAAVDTSSEITTKDL & -1.93122 & $<0.05$ \\
\hline D3ZX87 & LOC100910017 & KNLQTVNVDEN & -1.93203 & $<0.05$ \\
\hline D3ZUM4 & Glb1 & LELCTVEFVDTPVIG & -1.97941 & $<0.01$ \\
\hline Q6P9V9 & Tubalb & QPPTVVPGGDLAK & -2.01585 & $<0.05$ \\
\hline P63312 & Tmsb10 & ADKPDMGEIASFD & -2.02372 & $<0.001$ \\
\hline D4A269 & NA & ADEIAKAQVA & -2.02826 & $<0.001$ \\
\hline A0A0G2K890 & Ezr & APPPPPPPVYEPVN & -2.10935 & $<0.01$ \\
\hline F1LQ48 & Hnrnpl & DEGYGPPPPHYE & -2.13291 & $<0.01$ \\
\hline P08081 & Clta & APAGAPGGPALGN & -2.17074 & $<0.001$ \\
\hline P06761 & Hspa5 & MKETAEAYLGKK & -2.21256 & $<0.01$ \\
\hline Q62803 & Spam1 & LEDDLVNTIGEIV & -2.21478 & $<0.05$ \\
\hline P38552 & Lgals4 & IPAYPSAGYNPPQ & -2.21577 & $<0.01$ \\
\hline A0A0G2K6S9 & Myh11 & AQKGQLSDDEKF & -2.22383 & $<0.05$ \\
\hline P13437 & Acaa2 & SACIGGGQGISLIIQNTA & -2.23257 & $<0.01$ \\
\hline P30009 & Marcks & SPEAPPAPVAE & -2.24701 & $<0.001$ \\
\hline P45592 & Cfl1 & ASGVAVSDGVIK & -2.24734 & $<0.001$ \\
\hline O55212 & NA & DAGAAGGPGGPGGPGLG & -2.30987 & $<0.05$ \\
\hline D4AE06 & Fkbp15 & TPSVQPSLQPSHP & -2.32989 & $<0.05$ \\
\hline P62630 & Eefla1 & SGDAAIVDMVPGKP & -2.36181 & $<0.001$ \\
\hline P63269 & Actg2 & FAGDDAPRAVFPSIV & -2.37939 & $<0.05$ \\
\hline P62630 & Eefla1 & FAPVNVTTEVK & -2.45167 & $<0.01$ \\
\hline P30009 & Marcks & CSPEAPPAPVAE & -2.54825 & $<0.01$ \\
\hline
\end{tabular}


TABLE 1: Continued.

\begin{tabular}{|c|c|c|c|c|}
\hline Accession & Gene & Peptide & Fold change & $p$ value \\
\hline A0A0G2K3K2 & Actb & DSGDGVTHTVPIYE & -2.55819 & $<0.01$ \\
\hline D3ZFU9 & Mylk & AQPVGALKPIGN & -2.77191 & $<0.05$ \\
\hline P15865 & Hist1h1e & SETAPAAPAAPAPAEKTPIK & -2.77847 & $<0.001$ \\
\hline Q53Z83 & Mt1 & SCCSCCPVGCSKCAQGCVC & -2.79709 & $<0.05$ \\
\hline D3ZDZ1 & Apbblip & NFLPPPPPPP & -2.8025 & $<0.001$ \\
\hline P63312 & Tmsb10 & ADKPDMGEIAS & -2.84338 & $<0.001$ \\
\hline Q6URK4 & Hnrnpa3 & SPYGGGYGSGGGSGGY & -2.93019 & $<0.01$ \\
\hline Q10758 & Krt8 & GFGGAGVGGIT & -2.95692 & $<0.01$ \\
\hline P62630 & Eefla1 & VGEFEAGISKN & -2.98559 & $<0.001$ \\
\hline D3ZFU9 & Mylk & AKPAETLKPVGN & -2.98675 & $<0.01$ \\
\hline A0A0G2K890 & Ezr & APPPPPPPVYE & -3.14377 & $<0.001$ \\
\hline Q91W32 & Casp1 & KEGGAFPGPSGSLK & -3.15783 & $<0.001$ \\
\hline Q53Z83 & Mt1 & SCCSCCPVGCSKCAQGCVCKG & -3.27655 & $<0.01$ \\
\hline P06302 & Ptma & SDAAVDTSSEITTKDLK & -3.51799 & $<0.001$ \\
\hline B6ID08 & $\mathrm{Mt} 2 \mathrm{~A}$ & SCCSCCPVGCAKCSQGCICK & -3.56818 & $<0.05$ \\
\hline Q6P9V9 & Tubalb & LEPTVIDEVR & -3.6423 & $<0.001$ \\
\hline P62630 & Eefla1 & AGVGEFEAGISKN & -3.79477 & $<0.01$ \\
\hline D3ZJF8 & Fcgbp & CVAESTAVCRAQGD & -3.88626 & $<0.001$ \\
\hline A0A0G2K890 & Ezr & AELSSEGILDDRN & -3.89919 & $<0.05$ \\
\hline A0A0G2JUA5 & Ahnak & EGPEVDVSLP & -4.05973 & $<0.01$ \\
\hline Q53Z83 & Mt1 & CAQGCVCKGASDKCTCCA & -4.23021 & $<0.01$ \\
\hline Q63041 & Alm & AVDQSVLLLKPEAK & -4.3155 & $<0.001$ \\
\hline D3ZBN0 & Hist1h1b & GPPVSEL & -4.64319 & $<0.001$ \\
\hline P13668 & Stmn1 & ASSDIQVKELE & -4.88393 & $<0.01$ \\
\hline P97881 & Muc13 & GVPSQTSNPYAN & -5.02829 & $<0.001$ \\
\hline Q63041 & $\mathrm{A} 1 \mathrm{~m}$ & ALVQKDTVVKPVIVEPEG & -5.23966 & $<0.01$ \\
\hline Q6P9V9 & Tubalb & TVVPGGDL & -5.71525 & $<0.001$ \\
\hline P15865 & Histlhle & SETAPAAPAAPAPAEKTP & -6.05552 & $<0.001$ \\
\hline Q7M0E3 & Dstn & FLWAPEQAPLK & -6.43258 & $<0.01$ \\
\hline P62630 & Eef1a1 & ALPGDNVGFN & -6.78263 & $<0.001$ \\
\hline Q5PQK2 & Fus & YPTQPGQGYSQQSN & -8.52323 & $<0.05$ \\
\hline Q10758 & Krt8 & FGGAGVGGIT & -8.58147 & $<0.001$ \\
\hline P62630 & Eefla1 & APVNVTTEVK & -13.4474 & $<0.001$ \\
\hline P63269 & Actg2 & GQKDSYVGDEAQSKRG & -15.8726 & $<0.001$ \\
\hline
\end{tabular}

harvested and fixed with $4 \%$ paraformaldehyde for $1 \mathrm{~d}$ at room temperature. Following dehydration, embedding, sectioning, defatting, rehydration, and H\&E staining, the tissue sections were observed under a light microscope (Zeiss, Oberkochen, Germany).

2.7. Cell Culture. IEC-6 enterocytes were purchased from the American Type Culture Collection (ATCC, USA). The growth medium consisted of high glucose Dulbecco's Modified Eagle's medium (DMEM, Gibco BRL), 10\% fetal bovine serum (FBS, Gibco BRL), 1\% penicillinstreptomycin solution, and $0.1 \mathrm{U} / \mathrm{mL}$ recombinant human insulin. The cells were incubated at $37^{\circ} \mathrm{C}$ under $5 \% \mathrm{CO}_{2}$ and treated with $100 \mu \mathrm{g} / \mathrm{mL}$ LPS for $6 \mathrm{~h}$ to establish the NEC model in vitro.
2.8. Wound-Healing Assay. Cell migration was analyzed using the wound-healing assay. IEC- 6 cells were seeded in 6-well plates and cultured in DMEM containing 10\% FBS. On reaching confluency, the cell monolayer was scraped using sterile $1 \mathrm{~mL}$ pipette tips to form a uniform cell-free area. The wells were gently washed with sterile phosphatebuffered saline (PBS) to remove debris from the medium and monitored under an inverted microscope immediately (Eclipse TS100-F, Nikon) (0 h). Next, fresh medium was added to the wells, and the plates were incubated in the presence of EDP1 or MDP2 $(20 \mu \mathrm{m} / \mathrm{L})$ at $37^{\circ} \mathrm{C}$ for $12 \mathrm{~h}$ and monitored under an inverted microscope (12 h). Images taken at the $0 \mathrm{~h}$ and $12 \mathrm{~h}$ timepoints were expressed as the migration area, and the distances were measured using the ImageJ software v4.16. 
Downregulated

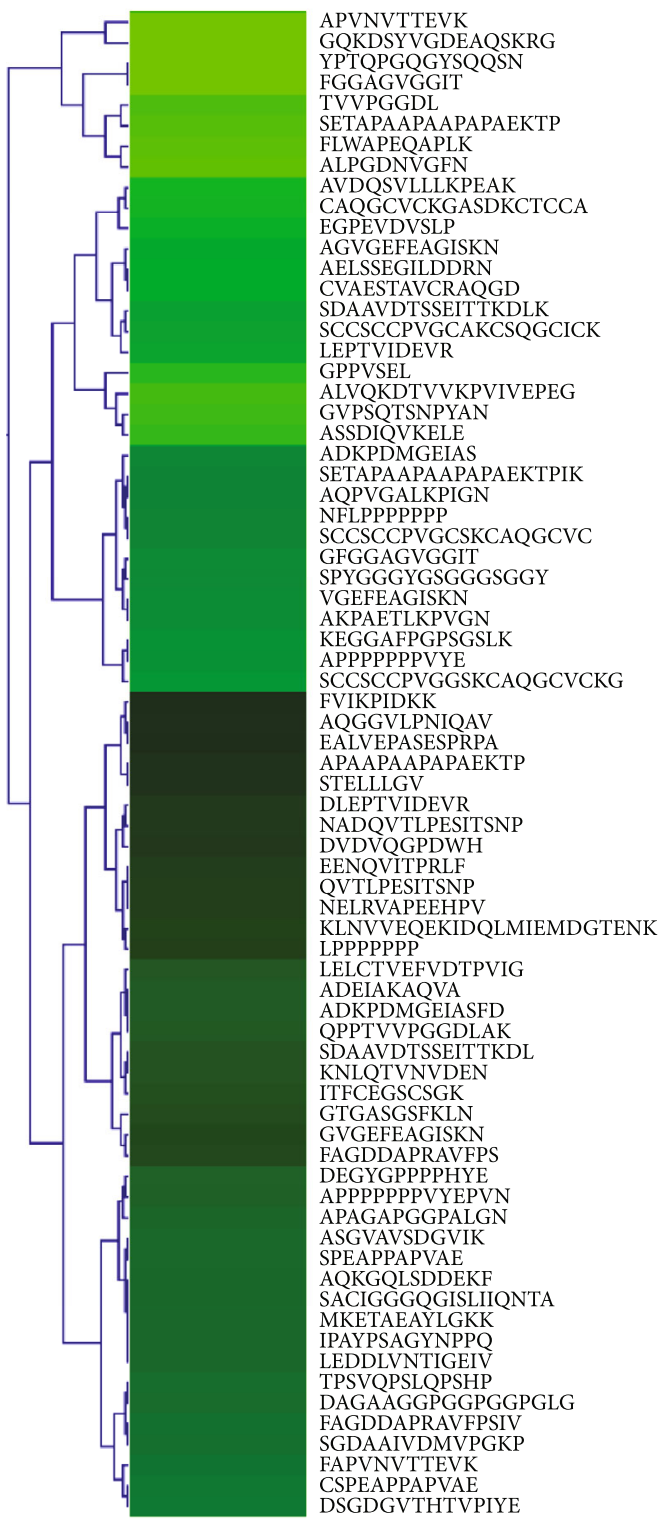

Upregulated

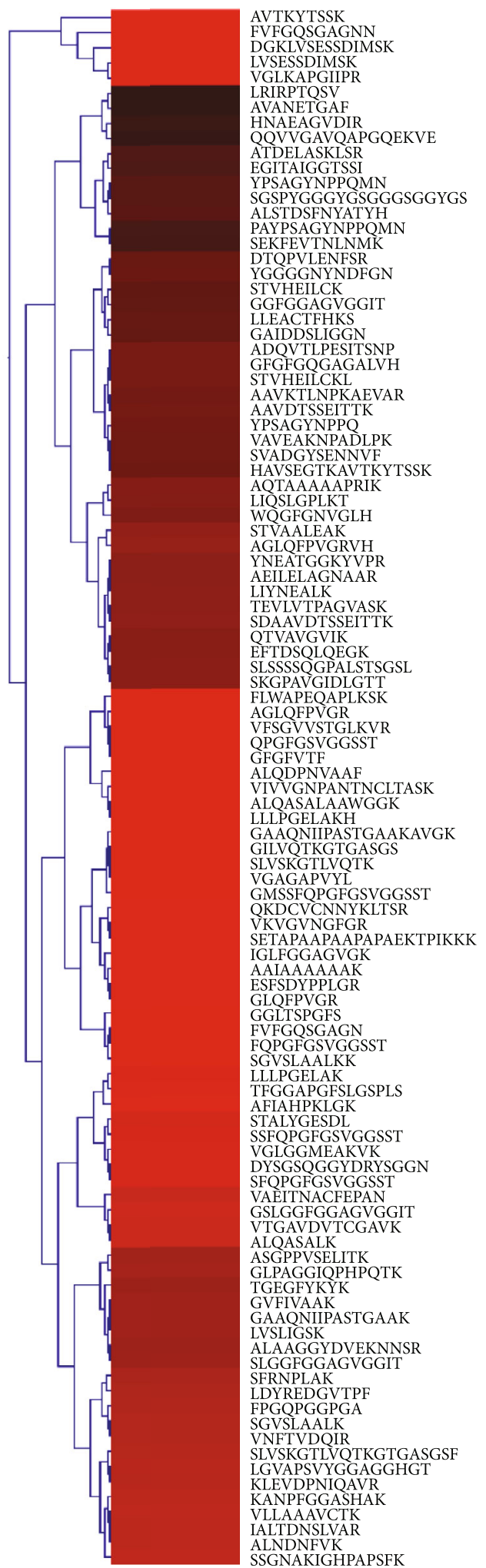

(a)

Figure 2: Continued. 


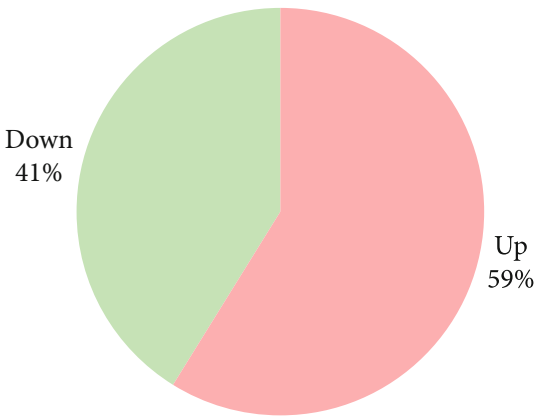

(b)

FIgURE 2: Differentially expressed intestinal peptides between Ctrl and NEC groups: (a) hierarchical cluster analysis of the differentially expressed peptides; (b) number of upregulated or downregulated peptides. The red color represents upregulation, and the green color represents downregulation; a darker color indicates a higher fold change.

2.9. Detection of Apoptosis. According to the manufacturer's instructions, an annexin V-fluorescein isothiocyanate (FITC)/propidium iodide (PI) cell apoptosis kit was used to detect the apoptosis level of the IEC-6 cells. In brief, after incubating the NEC in vitro model with EDP1 and MDP2 for $24 \mathrm{~h}$, the IEC- 6 cells were collected and washed with PBS, resuspended in $300 \mu \mathrm{L}$ binding buffer at a concentration of $1 \times 10^{6} / \mathrm{mL}$, and mixed with $3 \mu \mathrm{L}$ annexin $\mathrm{V}$-FITC and $3 \mu \mathrm{L}$ PI for $15 \mathrm{~min}$. A BD LSRII Flow Cytometer System with the FACS Diva Software was used to analyze the mixtures within $1 \mathrm{~h}$.

2.10. Statistical Analysis. All statistical analyses were performed using the SPSS statistical software. Student's $t$-test was used to assess significant differences between the two groups. Statistical comparisons between multiple groups were analyzed using ANOVA. Statistical significance was determined as $p<0.05$.

\section{Results}

3.1. Establishment of the NEC Model. Hypoxia-cold stimulation combined with hypertonic milk gavage was used to establish the NEC rat model. An optical microscope was used to observe stained intestinal tissue sections and evaluate the pathological score. The histopathological results showed shedding of the intestinal villi, submucosal edema, and inflammatory cell infiltration in the NEC group. In contrast, the intestinal mucosa epithelium was intact, the glands were arranged regularly, and edema and inflammatory cell infiltration were not evident in all layers of the intestinal wall in the Ctrl group (Figure 1(a)). In the NEC rat pups, the pathological score [13] was significantly higher than that in the Ctrl rat pups (Figure 1(b)). These findings revealed that the NEC model was successfully established.

3.2. Differentially Expressed Peptides in Intestinal Tissue Samples. TMT-labeled LC-MS/MS analysis was performed on peptides in the intestinal tissue samples from both the Ctrl and NEC groups. A total of 480 nonredundant peptides were identified, with 176 differentially expressed peptides derived from 91 protein precursors (fold change $\geq 1.5, p<0.05$ ).
Detailed information on these peptides is shown in Table 1. Upregulated or downregulated differentially expressed peptides were visualized in a hierarchical clustering heat map (Figure 2(a)). The number of upregulated or downregulated differentially expressed peptides is shown in Figure 2(b).

3.3. Characteristics of the Differentially Expressed Peptides. Some specific characteristics of the peptides were detected in this study. Among these characteristics, the amino acid numbers are mainly focused on 9-14 (Figure 3(a)), the peptides range largely from 800-1800 (Figure 3(b)), and the pI values are evenly distributed on both sides of acid and basic (Figure 3(c)). In addition, the distribution of MW relative to $\mathrm{pI}(\mathrm{MW} / \mathrm{pI})$ was investigated based on the amino acid composition and MW distribution specific to a pI (Figure 3(d)). As the generation of peptides mainly depends upon the enzymatic cleavage of precursor proteins [6], the cleavage site patterns of the identified peptides were analyzed (Figures 3(e) and 3(f)). Among the upregulated peptides, lysine $(\mathrm{K})$, arginine $(\mathrm{R})$, alanine $(\mathrm{A})$, and serine $(\mathrm{S})$ were the four dominant amino acids, whereas among the downregulated peptides, alanine $(A)$, lysine $(\mathrm{K})$, asparagine $(\mathrm{N})$, and glutamic acid (E) were the four dominant amino acids. In particular, we found that multiple peptides are derived from same precursor proteins. Among these, the precursor proteins Krt8, Eefla1, Hist1h1b, and NA generated a total of 31 peptides (Figure $3(\mathrm{~g})$ ).

3.4. GO and KEGG Pathway Analyses of the Differently Expressed Peptides. GO and KEGG pathway analyses were performed to determine the potential roles of these differentially expressed peptides and their corresponding precursor proteins. For biological processes, cellular developmental process, response to oxygen levels, regulation of cell development, NF- $\kappa$ B import into the nucleus, regeneration, and Wnt-activated receptor activity had a high enrichment score (Figure 4(a)). Extracellular exosome, myelin sheath, intracellular ribonucleoprotein complex, cell-cell adherens junction, membrane raft, and brush border as cellular components were found to be closely related to the identified peptides (Figure 4(b)). Regarding molecular function, Wnt-activated receptor activity, RNA polymerase II transcription factor 


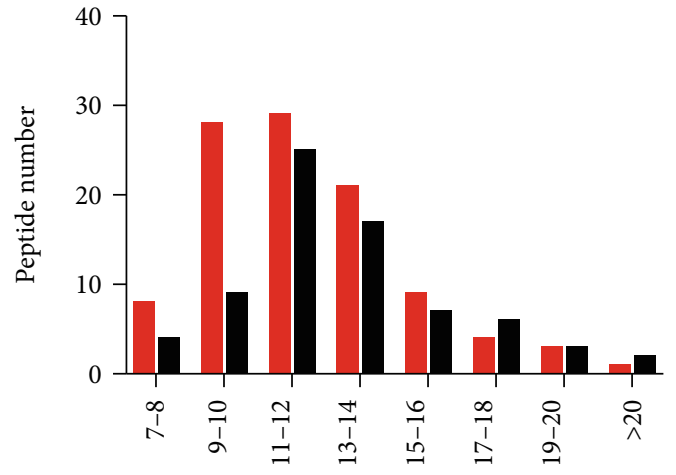

Amino Acid

Upregulated

Downregulated

(a)

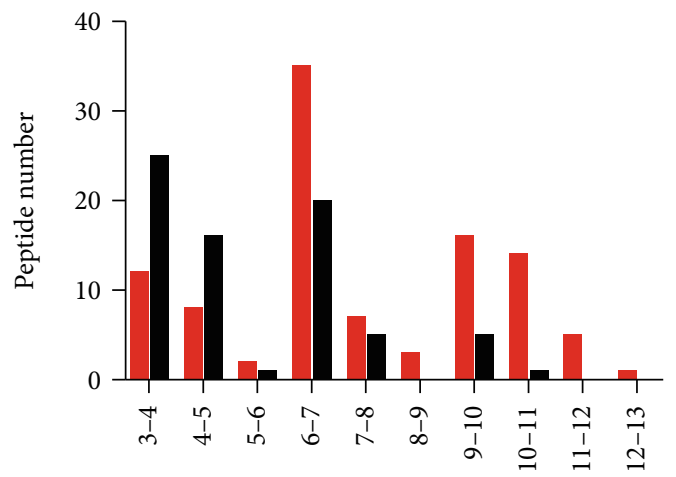

Isoelectric point (IP)

Upregulated

Downregulated

(c)

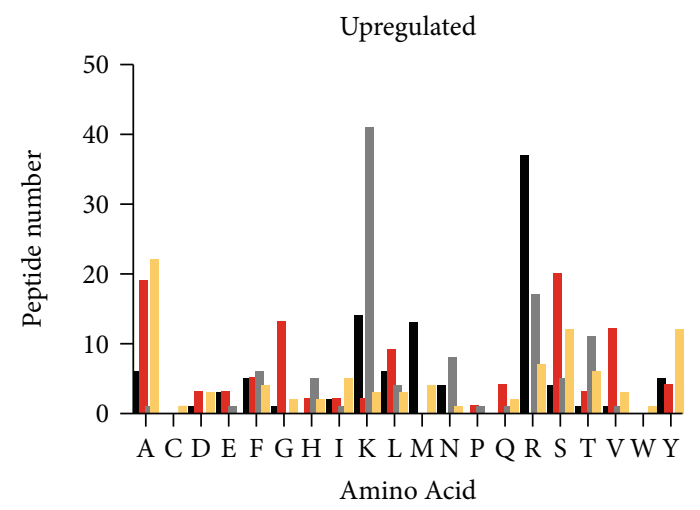

C-terminal amino acid of the preceding peptide $\mathrm{N}$-terminal amino acid of the identified peptide C-terminal amino acid of the identified peptide

N-terminal amino acid of the preceding peptide

(e)

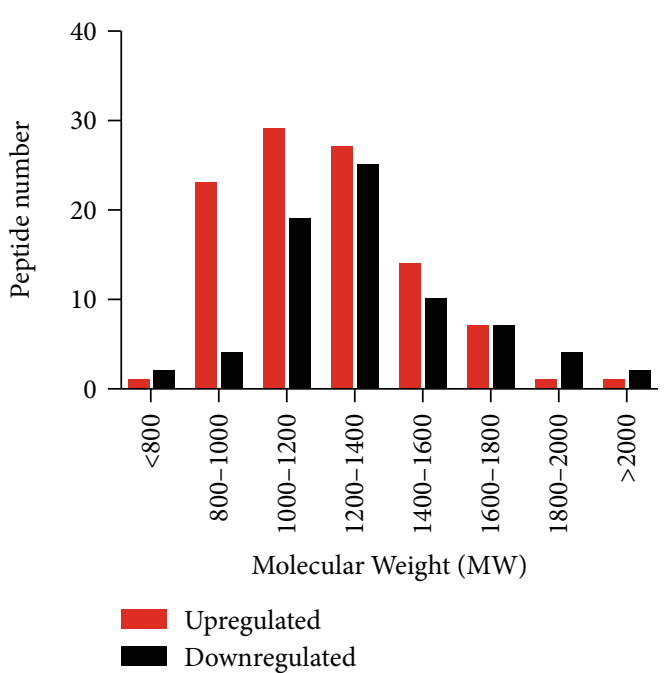

(b)

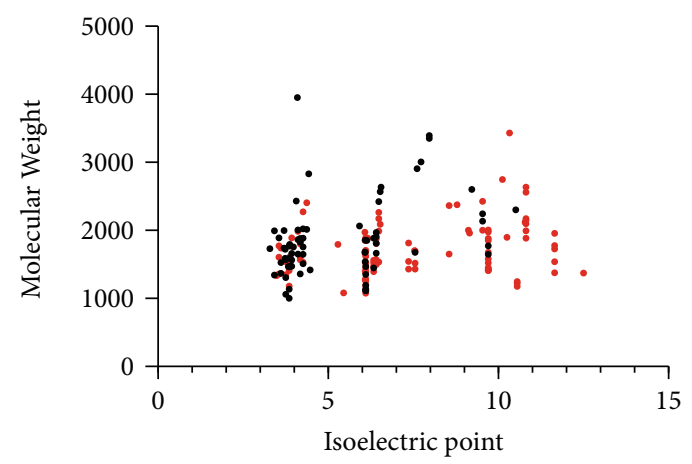

- Upregulated

- Downregulated

(d)

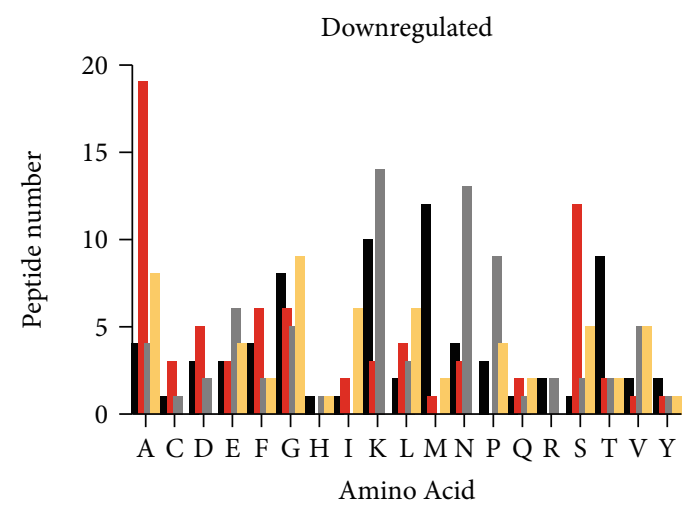

C-terminal amino acid of the preceding peptide $\mathrm{N}$-terminal amino acid of the identified peptide C-terminal amino acid of the identified peptide $\mathrm{N}$-terminal amino acid of the preceding peptide

(f)

Figure 3: Continued. 


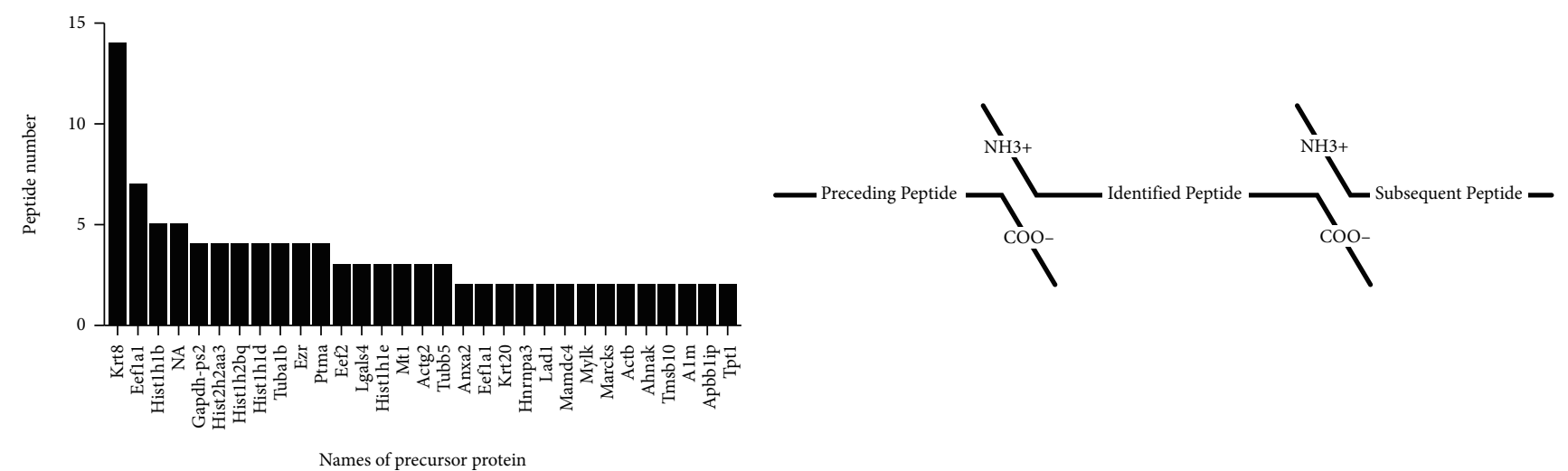

(g)

Figure 3: Characteristics of the differentially expressed peptides: (a) amino acid number, (b) molecular weights (MWs), and (c) isoelectric points (pI) of the peptides. (d) Scatter plot of MW versus pI. (e) The distribution diagram of the N- and C-terminal cleavage sites of the upregulated peptides. (f) The distribution diagram of the $\mathrm{N}$ - and C-terminal cleavage sites of the downregulated peptides. (g) The number of peptides produced by the same precursor proteins.

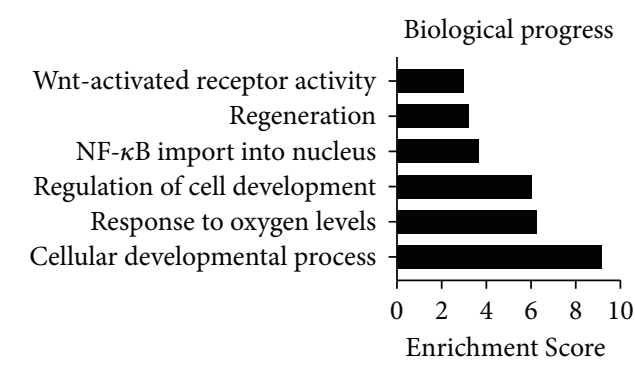

(a)

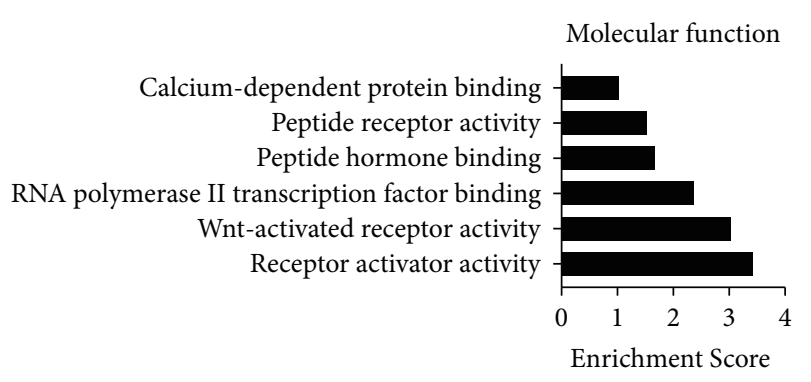

(c)

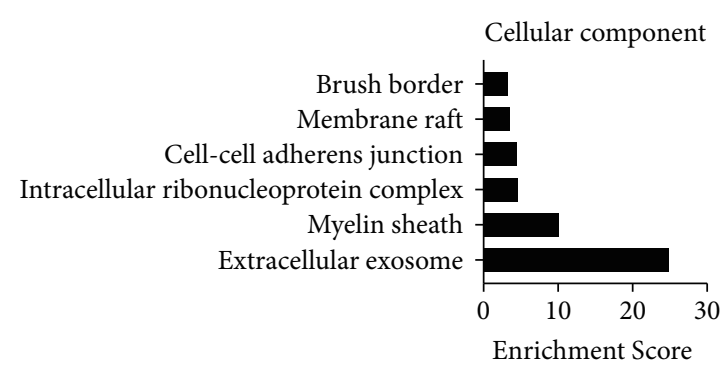

(b)

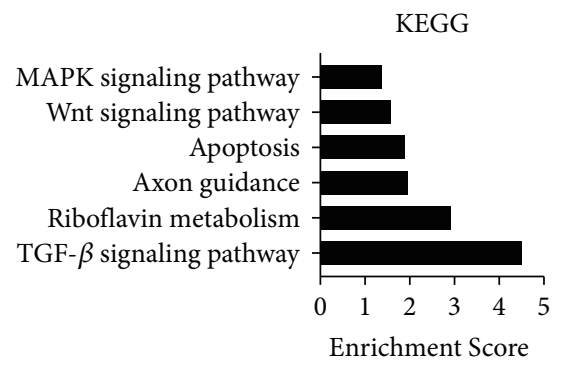

(d)

FIGURE 4: GO and KEGG pathway analyses of the differentially expressed peptides: (a) the biological process categories; (b) the cellular component categories; (c) the molecular function categories; (d) the KEGG signaling pathways.

binding, peptide hormone binding, peptide receptor activity, and calcium-dependent protein binding were identified as the most enriched subcategories (Figure 4(c)). Further, KEGG pathway analysis indicated that the potential function of these differentially expressed peptides was related to the TGF- $\beta$ signaling pathway, riboflavin metabolism, axon guidance, apoptosis, the Wnt signaling pathway, and the MAPK signaling pathway (Figure $4(\mathrm{~d})$ ).

3.5. Bioactive Peptides Potentially Related to NEC. The functions of the precursor proteins largely determine the functions of the bioactive peptides [14]. We used the UniProt and STRING databases to analyze the protein interactions of the differentially expressed peptides and the protein-protein interaction of their protein precursors. It is well known that bioactive peptides can be derived from their precursor domain. Hence, we used the UniProt database to analyze peptides derived from their precursor protein functional domain (Table 2). Among the downregulated peptides, the protein precursor Ezrin (Ezr) plays a vital role in the apical integrity of the intestinal epithelium, and its severe defects can lead to incomplete villi morphogenesis and neonatal death [15]. In addition, Metallothio (MT1) has a protective effect on intestinal mucosal inflammation. Therefore, we attempted to detect bioactive peptides with potential NEC protective effects from the downregulated peptides. 
TABLe 2: Differential peptides located in functional domains.

\begin{tabular}{|c|c|c|c|c|}
\hline Gene & Accession & Peptide & Peptide domain & $p$ value \\
\hline Hist1h2bq & G3V8B3 & AVTKYTSSK & Histone $\mathrm{H} 2 \mathrm{~B}$ & $<0.05$ \\
\hline Tubb5 & P69897 & FVFGQSGAGNN & Tubulin/FtsZ family, GTPase domain & $<0.01$ \\
\hline Mdh1 & O88989 & VIVVGNPANTNCLTASK & Ldh_1_N & $<0.05$ \\
\hline Aldob & Q66HT1 & ALQASALAAWGGK & Glycolytic & $<0.001$ \\
\hline Hist1h2bq & G3V8B3 & LLLPGELAKH & Histone $\mathrm{H} 2 \mathrm{~B}$ & $<0.001$ \\
\hline Eef2 & P05197 & VFSGVVSTGLKVR & GTP_EFTU_D2 & $<0.05$ \\
\hline Hnrnpa2b1 & F1LNF1 & GFGFVTF & RNA recognition motif & $<0.05$ \\
\hline Hist1h1d & M0R7B4 & SGVSLAALKK & Domain in histone families 1 and 5 & $<0.001$ \\
\hline Tubb5 & P69897 & FVFGQSGAGN & Tubulin/FtsZ family, GTPase domain & $<0.05$ \\
\hline Gapdh-ps2 & D3ZGY4 & GAAQNIIPASTGAAKAVGK & Gp_dh_C & $<0.001$ \\
\hline Hist1h1b & D3ZBN0 & SLVSKGTLVQTK & Domain in histone families 1 and 5 & $<0.01$ \\
\hline Hist1h1d & M0R7B4 & GILVQTKGTGASGS & Domain in histone families 1 and 5 & $<0.001$ \\
\hline NA & P02262 & VGAGAPVYL & Histone $2 \mathrm{~A}$ & $<0.001$ \\
\hline Atp5b & P10719 & IGLFGGAGVGK & ATPases associated with a variety of cellular activities & $<0.01$ \\
\hline Gapdh-ps2 & D3ZGY4 & VKVGVNGFGR & Glyceraldehyde 3-phosphate dehydrogenase, NAD binding domain & $<0.001$ \\
\hline Hist1h2bq & G3V8B3 & LLLPGELAK & Histone $\mathrm{H} 2 \mathrm{~B}$ & $<0.01$ \\
\hline Aldh18a1 & D3ZIE9 & VGLGGMEAKVK & AA_kinase & $<0.001$ \\
\hline Actn 4 & Q9QXQ0 & STALYGESDL & $\mathrm{Ca} 2+$ insensitive $\mathrm{EF}$ hand & $<0.001$ \\
\hline Krt8 & Q10758 & GSLGGFGGAGVGGIT & Keratin_2_head & $<0.05$ \\
\hline Aldoa & P05065 & ALQASALK & Glycolytic & $<0.01$ \\
\hline Plin3 & M0RA08 & VTGAVDVTCGAVK & Perilipin & $<0.001$ \\
\hline NA & A0A0G2K3Z9 & SSGNAKIGHPAPSFK & & $<0.01$ \\
\hline Gapdh-ps2 & D3ZGY4 & ALNDNFVK & Gp_dh_C & $<0.05$ \\
\hline Rps23 & P62268 & KANPFGGASHAK & Ribosom_S12_S23 & $<0.001$ \\
\hline Krt8 & Q10758 & KLEVDPNIQAVR & Keratin_2_head & $<0.001$ \\
\hline Hist $1 \mathrm{~h} 1 \mathrm{~b}$ & D3ZBN0 & SLVSKGTLVQTKGTGASGSF & Domain in histone families 1 and 5 & $<0.01$ \\
\hline Hist1h1d & M0R7B4 & SGVSLAALK & Domain in histone families 1 and 5 & $<0.01$ \\
\hline Tpt1 & P63029 & LDYREDGVTPF & TCTP & $<0.05$ \\
\hline Enol & Q5EB49 & SFRNPLAK & Enolase, C-terminal TIM barrel domain & $<0.05$ \\
\hline Psma1 & P18420 & LVSLIGSK & Proteasome & $<0.05$ \\
\hline Acaa2 & P13437 & GVFIVAAK & Thiolase_N & $<0.01$ \\
\hline Gapdh-ps2 & D3ZGY4 & GAAQNIIPASTGAAK & Gp_dh_C & $<0.001$ \\
\hline Krt8 & Q10758 & SLGGFGGAGVGGIT & Keratin_2_head & $<0.001$ \\
\hline Hadh & Q9WVK7 & TGEGFYKYK & $3 \mathrm{HCDH}$ & $<0.01$ \\
\hline Myh11 & A0A0G2K6S9 & STVAALEAK & & $<0.01$ \\
\hline Ptma & P06302 & SDAAVDTSSEITTK & Prothymosin & $<0.05$ \\
\hline Hist2h2aa3 & K7S2S2 & AEILELAGNAAR & Histone $2 \mathrm{~A}$ & $<0.01$ \\
\hline Tubb5 & P69897 & YNEATGGKYVPR & Tubulin/FtsZ family, GTPase domain & $<0.05$ \\
\hline Hspa8 & P63018 & SKGPAVGIDLGTT & HSP70 & $<0.05$ \\
\hline Eefla1 & P62630 & QTVAVGVIK & GTP_EFTU_D3 & $<0.05$ \\
\hline Glud1 & P10860 & VVQGFGNVGLH & Glutamate/leucine/phenylalanine/valine dehydrogenase & $<0.05$ \\
\hline Ptma & P06302 & AAVDTSSEITTK & Prothymosin & $<0.01$ \\
\hline Eef2 & P05197 & VAVEAKNPADLPK & EFG_II & $<0.01$ \\
\hline Wdr1 & Q5RKI0 & SVADGYSENNVF & WD40 repeats & $<0.001$ \\
\hline Hist1h2bq & G3V8B3 & HAVSEGTKAVTKYTSSK & Histone $\mathrm{H} 2 \mathrm{~B}$ & $<0.05$ \\
\hline Tpt1 & P63029 & GAIDDSLIGGN & TCTP & $<0.001$ \\
\hline Krt8 & Q10758 & GGFGGAGVGGIT & Keratin_2_head & $<0.05$ \\
\hline Efhd2 & Q4FZY0 & ATDELASKLSR & Metallothio & $<0.05$ \\
\hline
\end{tabular}


TABLE 2: Continued.

\begin{tabular}{|c|c|c|c|c|}
\hline Gene & Accession & Peptide & Peptide domain & $p$ value \\
\hline Pls1 & A0A0G2QC04 & EGITAIGGTSSI & & $<0.01$ \\
\hline Lgals2 & Q9Z144 & SEKFEVTNLNMK & Galactoside-binding lectin & $<0.05$ \\
\hline Fbxo10 & D3ZVN3 & HNAEAGVDIR & Parallel beta-helix repeats & $<0.05$ \\
\hline Vcp & P46462 & AVANETGAF & ATPases associated with a variety of cellular activities & $<0.001$ \\
\hline Ezr & A0A0G2K890 & FVIKPIDKK & & $<0.05$ \\
\hline Ahnak & A0A0G2JUA5 & DVDVQGPDWH & & $<0.01$ \\
\hline Tubalb & Q6P9V9 & DLEPTVIDEVR & Tubulin/FtsZ family, GTPase domain & $<0.05$ \\
\hline Eefla1 & P62630 & GVGEFEAGISKN & GTP_EFTU & $<0.01$ \\
\hline Ptma & P06302 & SDAAVDTSSEITTKDL & Prothymosin & $<0.05$ \\
\hline Tmsb10 & P63312 & ADKPDMGEIASFD & Thymosin beta actin-binding motif. & $<0.001$ \\
\hline Hspa5 & P06761 & MKETAEAYLGKK & HSP 70 & $<0.01$ \\
\hline Spam1 & Q62803 & LEDDLVNTIGEIV & Glyco_hydro_56 & $<0.05$ \\
\hline Myh11 & A0A0G2K6S9 & AQKGQLSDDEKF & & $<0.05$ \\
\hline Acaa2 & P13437 & SACIGGGQGISLIIQNTA & Thiolase_C & $<0.01$ \\
\hline Eef1a1 & P62630 & SGDAAIVDMVPGKP & GTP_EFTU_D3 & $<0.001$ \\
\hline $\operatorname{Actg} 2$ & P63269 & FAGDDAPRAVFPSIV & Actin & $<0.05$ \\
\hline Actb & $\mathrm{A} 0 \mathrm{~A} 0 \mathrm{G} 2 \mathrm{~K} 3 \mathrm{~K} 2$ & DSGDGVTHTVPIYE & & $<0.01$ \\
\hline Tmsb10 & P63312 & ADKPDMGEIAS & Thymosin beta actin-binding motif. & $<0.001$ \\
\hline Krt8 & Q10758 & GFGGAGVGGIT & Keratin_2_head & $<0.01$ \\
\hline Eefla1 & P62630 & VGEFEAGISKN & GTP_EFTU & $<0.001$ \\
\hline Ptma & P06302 & SDAAVDTSSEITTKDLK & Prothymosin & $<0.001$ \\
\hline Tuba1b & Q6P9V9 & LEPTVIDEVR & Tubulin/FtsZ family, GTPase domain & $<0.001$ \\
\hline Eef1a1 & P62630 & AGVGEFEAGISKN & GTP_EFTU & $<0.01$ \\
\hline Fcgbp & D3ZJF8 & CVAESTAVCRAQGD & von Willebrand factor (vWF) type D domain & $<0.001$ \\
\hline Ahnak & A0A0G2JUA5 & EGPEVDVSLP & & $<0.01$ \\
\hline Mt1 & Q53Z83 & CAQGCVCKGASDKCTCCA & Metallothio & $<0.01$ \\
\hline A1m & Q63041 & AVDQSVLLLKPEAK & Alpha-2-macroglobulin & $<0.001$ \\
\hline Stmn1 & P13668 & ASSDIQVKELE & Stathmin & $<0.01$ \\
\hline Eefla1 & P62630 & ALPGDNVGFN & GTP_EFTU_D2 & $<0.001$ \\
\hline Krt8 & Q10758 & FGGAGVGGIT & Keratin_2_head & $<0.001$ \\
\hline
\end{tabular}

3.6. Protective Effects of EDP1 and MDP2. To further analyze the function of the differentially expressed peptides, we randomly selected downregulated peptide 1 derived from EZRI (EDP1) and downregulated peptide 2 derived from MT1 (MDP2) to investigate its NEC protective ability. Interestingly, EDP1 treatment could partially reverse the inhibition of cell migration caused by LPS (Figures 5(a) and 5(b)). In addition, MDP2 treatment not only reversed the inhibition of cell migration in the NEC cell model but also decreased the apoptosis level (Figures 5(a) and 5(b)).

\section{Discussion}

NEC is the most common gastrointestinal complication in premature infants [16]. Although extensive research has been conducted to investigate this disease, the underlying molecular mechanisms have not yet been fully elucidated. Peptidomics is an innovative branch of proteomics, which has been used to explore the mechanisms of various diseases [17,
18]. In our study, we detected differentially expressed peptides in intestinal tissues that were further analyzed for their potential association with NEC. Moreover, the bioactive peptides EDP1 and MDP2 showed a protective effect in the NEC model in vitro.

In total, 176 differentially expressed peptides, including 103 upregulated and 73 downregulated, were identified. GO analysis of precursor proteins revealed that the differentially expressed peptides were mainly involved in the response to oxygen levels, NF- $\kappa \mathrm{B}$ import into the nucleus, extracellular exosome, intracellular ribonucleoprotein complex, cell-cell adherens junction, peptide hormone binding, and peptide receptor activity. Among these, accumulation of oxygen free radicals and low antioxidant capacity result in intestinal epithelial cell apoptosis and intestinal inflammation, which are the known causes of NEC [19]. Moreover, the aberrant activation of NF- $\kappa \mathrm{B}$ has been shown to be associated with many inflammatory bowel diseases, including NEC, and the inhibition of NF- $\kappa$ B can reduce intestinal damage [20]. Further, 


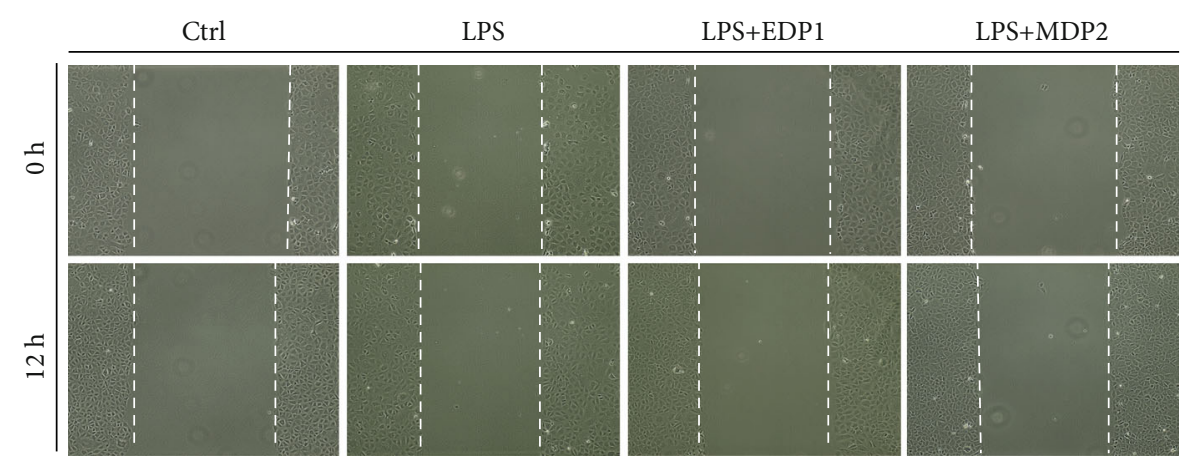

(a)
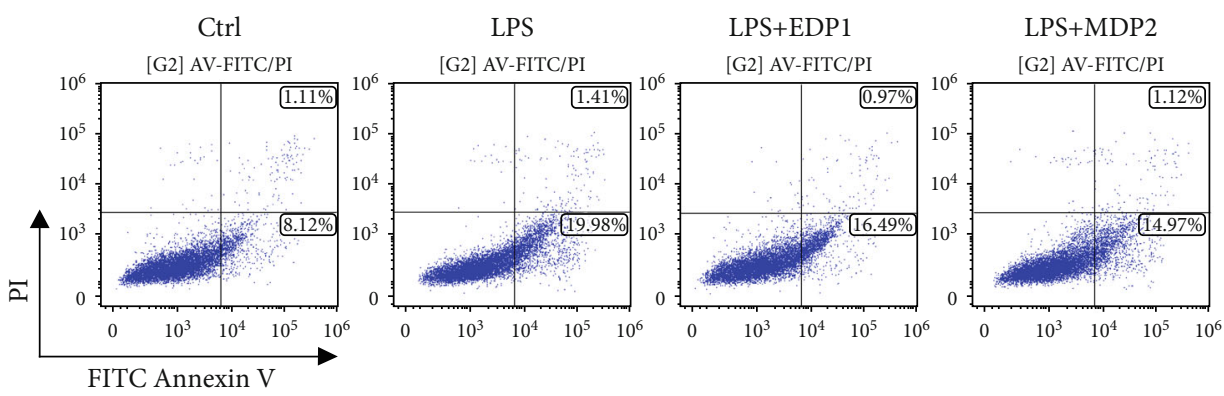

(b)
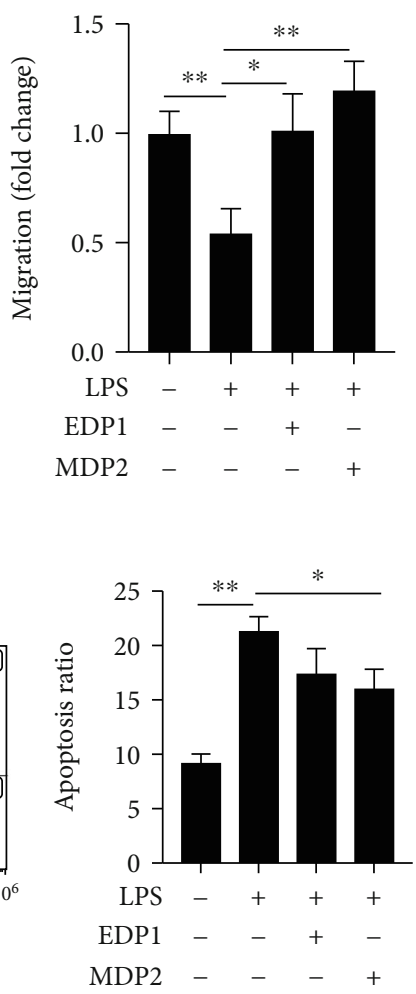

FIGURE 5: Protective effects of EDP1 and MDP2: (a) the effect of EDP1 and MDP2 on the NEC in vitro model wound restitution; (b) the effect of EDP1 and MDP2 on the NEC in vitro model apoptosis ratio.

exosomes partially assumed the function of the local and long-distance communication of cells. These results revealed that the differentially expressed peptides are involved in the pathological mechanism of NEC.

KEGG analysis revealed that the TGF- $\beta$ signaling pathway, apoptosis, and the Wnt signaling pathway had a high enrichment score. It is well known that the main feature of NEC is hemorrhagic and necrotizing inflammation within all layers of the intestinal wall [21]. As a pleiotropic cytokine, TGF- $\beta$ can regulate multiple cellular functions and suppress immune responses [22]. In intestinal immunity, TGF- $\beta$ plays a role in suppressing the strong inflammatory response in the intestinal cavity and promotes the construction of immune tolerance, thereby exerting a protective effect in inflammatory bowel diseases [23]. The destruction of the dynamic barrier between the intestinal epithelial layer and the substances in the intestinal cavity is an important process in NEC pathogenesis [24]. Widespread intestinal epithelial cell death is the key mechanism leading to this damage. Studies have reported high levels of intestinal cell apoptosis in the established NEC animal model; moreover, the effect of caspase inhibitors on apoptosis prevents NEC progression. The renewal of intestinal stem cells is a protective response of the intestine to acute injury. Intestinal renewal as well as stem cell maintenance depends mainly on the $\mathrm{Wnt} / \beta$ catenin pathway [25]. Studies have found that $\mathrm{Wnt} / \beta$ catenin signaling decreases during NEC development [26, 27]. This leads to impaired intestinal stem cell activity and poor intestinal regeneration ability. However, the administration of Wnt can maintain intestinal epithelial homeostasis and avoid the intestinal injury observed in NEC [28]. These results indicate that the differentially expressed peptides may be potentially involved in the mechanism underlying NEC.

Recently, an increasing number of peptides have been found to exert a protective effect in intestinal diseases. For instance, vasoactive intestinal peptides (as effective antiinflammatory agents) exhibited the ability to regulate homeostasis of the intestinal epithelial barrier. It serves a therapeutic role by reducing inflammation and destroying tight junctions in NEC [29]. In addition, a peptide derived from Porphyra yezoensis was able to promote IEC-6 cell proliferation through the activation of insulin-like growth factor I receptors [30]. However, there are no reports about the treatment of NEC with endogenous active peptides.

In our study, peptides derived from the precursor proteins EZRI and MT1 were significantly downregulated in the NEC group. We initially synthesized two peptides EDP1 and MDP2 from the functional domains of Ezrin and Metallothio, respectively. We found that the peptide EDP1 promotes cell migration after acting on the NEC model in vitro, whereas the peptide MDP2 promotes cell migration and inhibits apoptosis in the NEC model in vitro. These results indicate that bioactive peptides are involved in the progression of NEC; however, the mechanisms underlying the peptide functions need to be further investigated. 


\section{Conclusion}

In conclusion, we initially screened the differentially expressed peptides in the intestinal tissues of the NEC rat model based on TMT markers combined with LC-MS/MS analysis. Next, we investigated the pathological mechanism of NEC and explored the potential treatment strategies. Although the peptides EDP1 and MDP2 were confirmed to exhibit protective effects in NEC, we need to explore their therapeutic mechanisms further.

\section{Data Availability}

The data that support the findings of this study are available from the corresponding author upon reasonable request.

\section{Conflicts of Interest}

The authors declare that there is no conflict of interest regarding the publication of this paper.

\section{Authors' Contributions}

Yiwen Liu, Changlin Wang, Renqiang Yu, and Jianfeng Fan contributed equally.

\section{Acknowledgments}

The authors acknowledge support from the National Natural Science Foundation of China (Grant No. 81901517), the Wuxi Key Medical Disciplines (Grant No. ZDXK12, FZXK001), the Medical Innovation Team of Jiangsu Province (Grant No. CXTDB2017016), the Wuxi Young Medical Talents (Grant No. QNRC094, QNRC089), the Wuxi Hospital Management Center Key Project (Grant No. YGZXZ1513), the Wuxi Hospital Management Center Joint Research Project (Grant No. YGZXL1319), the Young project of Wuxi health and Family Planning Commission (Grant No. Q201815, Q201760, Q201604), the Jiangsu maternal and child health research project (Grant No. F201852), the Wuxi Science and Technology Development Fund (Grant No. N20192039, N20202003), the Project of Wuxi health Commission (Grant No. M202003), and the Wuxi Young and Middle-aged Medical Talents (Grant No. BJ2020089).

\section{References}

[1] A. M. Thompson and M. J. Bizzarro, "Necrotizing enterocolitis in newborns: pathogenesis, prevention and management," Drugs, vol. 68, no. 9, pp. 1227-1238, 2008.

[2] J. Neu and W. A. Walker, "Necrotizing enterocolitis," The New England Journal of Medicine, vol. 364, no. 3, pp. 255-264, 2011.

[3] S. C. Fitzgibbons, Y. Ching, D. Yu et al., "Mortality of necrotizing enterocolitis expressed by birth weight categories," Journal of Pediatric Surgery, vol. 44, no. 6, pp. 1072-1076, 2009.

[4] M. Good, C. P. Sodhi, C. E. Egan et al., "Breast milk protects against the development of necrotizing enterocolitis through inhibition of Toll-like receptor 4 in the intestinal epithelium via activation of the epidermal growth factor receptor," Mucosal Immunology, vol. 8, no. 5, pp. 1166-1179, 2015.
[5] I. Schulte, H. Tammen, H. Selle, and P. Schulz-Knappe, "Peptides in body fluids and tissues as markers of disease," Expert Review of Molecular Diagnostics, vol. 5, no. 2, pp. 145-157, 2005.

[6] A. M. Lone, Y. G. Kim, and A. Saghatelian, "Peptidomics methods for the identification of peptidase-substrate interactions," Current Opinion in Chemical Biology, vol. 17, no. 1, pp. 83-89, 2013.

[7] A. B. Leichtle, J. F. Dufour, and G. M. Fiedler, "Potentials and pitfalls of clinical peptidomics and metabolomics," Swiss Medical Weekly, vol. 143, article w13801, 2013.

[8] K. G. Murphy, W. S. Dhillo, and S. R. Bloom, "Gut peptides in the regulation of food intake and energy homeostasis," Endocrine Reviews, vol. 27, no. 7, pp. 719-727, 2006.

[9] R. Carrasco, M. Pera, F. E. B. May, B. R. Westley, A. Martinez, and L. Morales, "Trefoil factor family peptide 3 prevents the development and promotes healing of ischemia-reperfusion injury in weanling rats," Journal of Pediatric Surgery, vol. 39, no. 11, pp. 1693-1700, 2004.

[10] Y. Hou, X. Lu, and Y. Zhang, "IRAK inhibitor protects the intestinal tract of necrotizing enterocolitis by inhibiting the toll-like receptor (TLR) inflammatory signaling pathway in rats," Medical Science Monitor, vol. 24, pp. 3366-3373, 2018.

[11] Y. G. Kim, A. M. Lone, and A. Saghatelian, "Analysis of the proteolysis of bioactive peptides using a peptidomics approach," Nature Protocols, vol. 8, no. 9, pp. 1730-1742, 2013.

[12] X. Wang, S. Xu, L. Chen et al., "Profiling analysis reveals the potential contribution of peptides to human adipocyte differentiation," Proteomics Clin Appl, vol. 12, no. 6, article e1700172, 2018.

[13] S. R. Shiou, Y. Yu, S. Chen et al., "Erythropoietin protects intestinal epithelial barrier function and lowers the incidence of experimental neonatal necrotizing enterocolitis," The Journal of Biological Chemistry, vol. 286, no. 14, pp. 1212312132, 2011.

[14] E. S. Ferro, V. Rioli, L. M. Castro, and L. D. Fricker, "Intracellular peptides: from discovery to function," EuPA Open Proteomics, vol. 3, no. C, pp. 143-151, 2014.

[15] J. B. Casaletto, I. Saotome, M. Curto, and A. I. McClatchey, "Ezrin-mediated apical integrity is required for intestinal homeostasis," Proceedings of the National Academy of Sciences of the United States of America, vol. 108, no. 29, pp. 1192411929, 2011.

[16] S. Martini, A. Aceti, M. Lima, M. Maffi, G. Faldella, and L. Corvaglia, "Octreotide in a critically ill extremely preterm infant with perforated necrotizing enterocolitis," Pediatrics, vol. 138, no. 2, article e20160467, 2016.

[17] N. Srairi-Abid, H. Othman, D. Aissaoui, and R. BenAissa, "Anti-tumoral effect of scorpion peptides: emerging new cellular targets and signaling pathways," Cell Calcium, vol. 80, pp. 160-174, 2019.

[18] X. Li, J. Li, B. Zhang et al., "Comparative peptidome profiling reveals critical roles for peptides in the pathology of pancreatic cancer," The International Journal of Biochemistry \& Cell Biology, vol. 120, p. 105687, 2020.

[19] M. Kim, S. Christley, J. C. Alverdy, D. Liu, and G. An, "Immature oxidative stress management as a unifying principle in the pathogenesis of necrotizing enterocolitis: insights from an agent-based model," Surgical Infections, vol. 13, no. 1, pp. 18-32, 2012.

[20] I. G. de Plaen, S. X. L. Liu, R. Tian et al., "Inhibition of nuclear factor- $\kappa \mathrm{B}$ ameliorates bowel injury and prolongs survival in a 
neonatal rat model of necrotizing enterocolitis," Pediatric Research, vol. 61, no. 6, pp. 716-721, 2007.

[21] M. J. Müller, T. Paul, and S. Seeliger, "Necrotizing enterocolitis in premature infants and newborns," Journal of NeonatalPerinatal Medicine, vol. 9, no. 3, pp. 233-242, 2016.

[22] P. Biancheri, P. Giuffrida, G. H. Docena, T. T. MacDonald, G. R. Corazza, and A. Di Sabatino, "The role of transforming growth factor (TGF)- $\beta$ in modulating the immune response and fibrogenesis in the gut," Cytokine \& Growth Factor Reviews, vol. 25, no. 1, pp. 45-55, 2014.

[23] S. Ihara, Y. Hirata, and K. Koike, "TGF- $\beta$ in inflammatory bowel disease: a key regulator of immune cells, epithelium, and the intestinal microbiota," Journal of Gastroenterology, vol. 52, no. 7, pp. 777-787, 2017.

[24] E. A. Deitch, "Role of bacterial translocation in necrotizing enterocolitis," Acta Paediatrica Supplement, vol. 83, no. s396, pp. 33-36, 1994.

[25] J. Schuijers and H. Clevers, "Adult mammalian stem cells: the role of Wnt, Lgr5 and R-spondins," The EMBO Journal, vol. 31, no. 12, pp. 2685-2696, 2012.

[26] S. M. Tanner, T. F. Berryhill, J. L. Ellenburg et al., "Pathogenesis of necrotizing enterocolitis: modeling the innate immune response," The American Journal of Pathology, vol. 185, no. 1, pp. 4-16, 2015.

[27] M. Good, C. P. Sodhi, Y. Yamaguchi et al., "The human milk oligosaccharide 2'-fucosyllactose attenuates the severity of experimental necrotising enterocolitis by enhancing mesenteric perfusion in the neonatal intestine," The British Journal of Nutrition, vol. 116, no. 7, pp. 1175-1187, 2016.

[28] B. Li, C. Lee, M. Cadete et al., "Impaired Wnt/ $\beta$-catenin pathway leads to dysfunction of intestinal regeneration during necrotizing enterocolitis," Cell Death \& Disease, vol. 10, no. 10, p. 743, 2019.

[29] S. Seo, H. Miyake, M. Alganabi et al., "Vasoactive intestinal peptide decreases inflammation and tight junction disruption in experimental necrotizing enterocolitis," Journal of Pediatric Surgery, vol. 54, no. 12, pp. 2520-2523, 2019.

[30] M. K. Lee, I. H. Kim, Y. H. Choi, and T. J. Nam, "A peptide from Porphyra yezoensis stimulates the proliferation of IEC6 cells by activating the insulin-like growth factor I receptor signaling pathway," International Journal of Molecular Medicine, vol. 35, no. 2, pp. 533-538, 2015. 